\title{
Designing Phygital Activities In a Smart Multisensorial Room: a Collaborative Cognitive Environment for Children with and without Disabilities
}

\begin{abstract}
Technology integration in education has a great potential to transform learning paths, to overcome barriers and increase meaningful interactions among students, teachers, and the environment. Phygital learning is an emerging approach that balances the innovative technology-driven experience content with the traditional and physical one. In the context of Inclusive Education, this approach is particularly promising for enhancing the learning domains (cognitive, affective, and psychomotor) of children with disabilities. Recognized as integrators in multidisciplinary teams, characterized by a broad vision on users' needs and experience, and familiar with the creative problemsolving process, designers can have an active role in developing new learning activities. This paper describes the development of Magika, an interactive Multisensory Environment, that supports inclusive education via playful phygital (physical + digital) activities for children with and without disabilities. 30 specialists, among product and interior designers, electronic, materials and mechanical engineers, primary educators, therapist, and caregivers, were involved in a co-design process to define the educational and therapeutic objectives of phygital activities, according to the Italian primary school education system.
\end{abstract}

\section{Keywords}

Multisensory Environment, Environmental Design, User Experience, Phygital Learning, Design For All

\section{Introduction}

Inclusive Education is a fundamental point in the Italian education system, even though schools are not well equipped with spaces for learning, play, and socialization specifically designed for children with disabilities. In this context, our research aims at supporting and developing activities for children with physical and intellectual disabilities (ID). We design activities for LUDOMI project, one of the winners of the Politecnico Social Award of 2017 [36], whose goal is to provide multisensory smart rooms for schools. The project strengths are on the one hand the innovative interactions for users and on the other hand the multidisciplinary approach of the project, which allow merging different competences starting from system integration skills to expressive-sensorial properties knowledge of the materials. The output of the cooperative collaboration between therapist, educators, and caregivers is Magika, a smart multisensory room that supports inclusive education via different phygital (physical + digital) activities. 
Role of designer. By their nature, designers are connectors and facilitators in transdisciplinary dialogues between different knowledge [1]. The designer profile continues to evolve according with the complexity of the context in which he works, our society [2]: design discipline has become "adult" and its problemsolving process (design-thinking) is commonly applied by other professionals to design products, services and experiences, innovation processes, business models and strategies [3]. The evolution that industrial designers have experienced includes a significant change in practice, that is not limited to just design thinking [4]: from a strongly "artistic-intuitive" practice to research and validation-based one [5]. The involvement of designers in the processes of functional materials development [6-8], or in social innovation projects, is predominant also in companies which are examples of this change. Designers have always had a special relationship with materials and artifacts' materiality [9], [10]. Today, industrial designers play an active role in shifting towards a "radical" process of material development [11]: from practical experimentation to materials properties, from reflecting on materials quality to expanding the meaning of materials.

Paper structure. This paper presents the conceptual framework used to design phygital activities that integrate the tactile sensory perception to empower learning through sensory-motor experiences. In this perspective, we want to shed light on the role of the designer in a technological environment for social innovation. Firstly, we describe the integration role of the designer in an interactive environment, then we focus on the main features of Magika, and we delineate the guidelines for designing phygital activities in a such innovative interactive environment.

\section{Smart Multisensory Room}

Background. Multisensory environment's rationale is grounded on the theories of embodied cognition and sensory integration that emphasizes the formative role of embodiment in the development of cognitive skills such as mental imagery, reasoning and problem-solving [33]. Specific interventions for persons with special needs aim at stimulating basic perceptual mechanisms and promoting perceptual learning [33]. They often take place in a dedicated Multi-Sensory Environment (often referred to as Snoezelen [34]) - a room equipped to provide gentle multisensory stimulations through sounds, lights, projections, soft fabrics, and materials. Prior research indicates that combining the physical and the digital world and offering multisensory stimuli through embodied interaction provides support for persons with disabilities. MEDIATE [35] generates sound and visual stimuli in response to gestures and footsteps on the floor in front of a large display and would stimulate low-functioning non-verbal children with autism. In this framework, in a multisensory room, we designed phygital (physical + digital) activities, which refer to tasks in a physical environment that a user can physically interact with to manipulate digital information. This work sheds light on the potential of phygital approach in a multisensory room. According to Antle [24] and Falcao [25], the possibilities provided by tangible interfaces, such as physical manipulation, physical-digital mappings, exploration, and collaboration, represent promising opportunities for learning. Eisenberg et al. [26] also support the fact that tangible technologies provide richer sensory experiences through the interweaving of computation and physical materials, extending the intellectual and emotional potential of people's artifacts and integrating expressive aspects of traditional educational technologies with educational properties of physical objects.

Materials are at the core of any physical artifact, and not only they contribute to its function, but they also have aesthetic and emotional values that allow designers to shape the character of a product. Among different material features, expressive-sensorial properties [27] are the ones embodied in the 'skin' of a product [28] and can be related to users' experiences with and through materials [29]. These properties are usually, but not always consciously, evaluated by product designers when selecting materials and finishes. The surface features that can be perceived by the human senses as linked to a material's physical properties [30] are named sensorial properties. On the other hand, if such features are largely linked to a product's value and identity, or user experience and preference, they are identified as intangible properties. Karana et al. [31] focus on materials having a dual meaning, one that emphasizes the role of materials as being technical and the other experiential. One of the pioneers of the material experience both in a sensory and intangible way is Bruno Munari [32], 

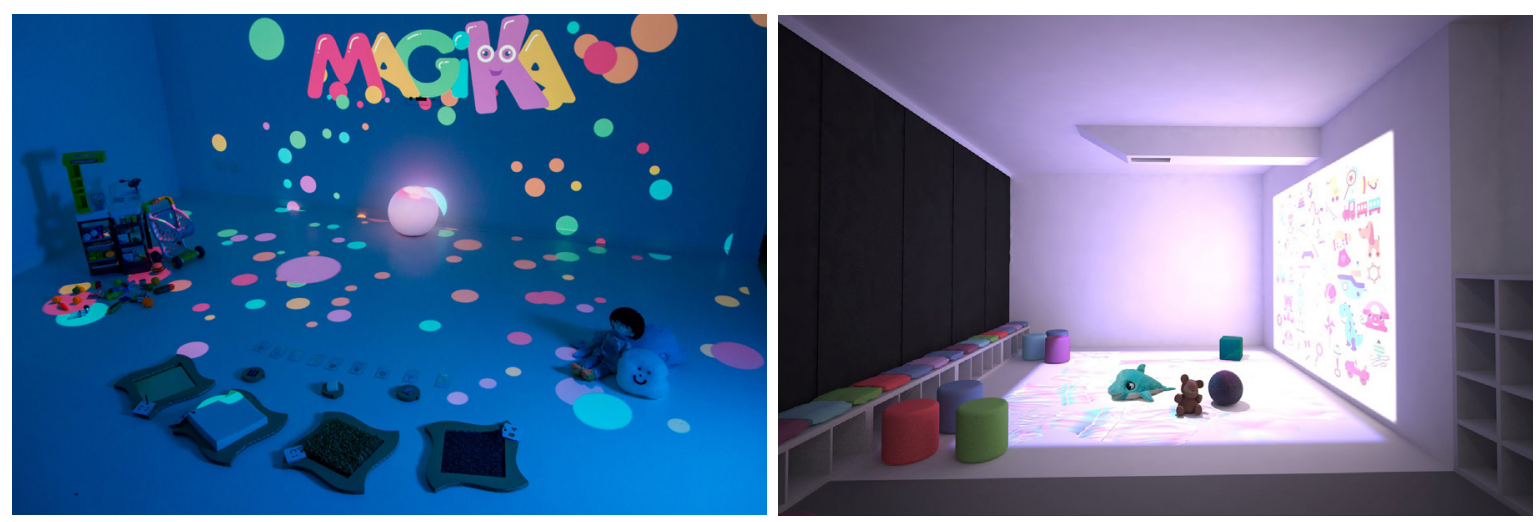

a designer and a design educator who gave great contribution to Design in reinforcing creative thinking in design education as experimental investigations.

Introducing Magika. Magika [13] combines and extends the features of existing multisensory digital systems, proposing an inter-connected space where all children are involved in new forms of full-body, playful, multi-sensory, learning experiences. Magika's primary stakeholders are children from 4 to 10 years old, especially those with disabilities. They present physical, psychological, sensory impairments that cause a learning difficulty and a situation of marginalization [23].

Secondary stakeholders are support teachers, teachers, psychologists, therapists, eventually parents, and the community overall. We developed a technology, Magika, that transforms an empty room into a multisensory room (Figure 1) that integrates visual contents projected on the walls and the floor, ambient sound, smart physical objects, connected appliances, smart lights. These elements, controlled using a tablet and automated by a PC, react to children's manipulation and body movements (touchless interaction provided by a Microsoft Kinect) to offer visual, auditory, tactile, and olfactory stimuli in any sequence and combination.

\section{Guidelines for Phygital Activities Design}

Since Magika is a multisensory room where children explore the environment through different senses, we introduced tactile exploration. Phygital activities have been chosen as the proper channel to explore the physical world interacting with digital inputs and feedback, and, moreover, this environment gives the children the opportunity to learn sensory association connected to the tactile experience. In the next sections, we describe the design process of activities, starting from the objectives up to the definition of a phygital activity framework.

Requirements Elicitation. We decided to test the phygital approach with therapists and teachers to clearly evaluate its potential. We decided to opt for a focus group to commit therapists and teachers directly and promote cooperation. Due to the long-term fruitful collaboration, all participants ( 3 therapists, 3 teachers, 2 designers, 2 software engineers) felt comfortable and confident in speaking openly and frankly. The focus group started with a description phase, in which the multisensory room was shown. We asked specialists to impersonate into their therapy or educational session with children with and without disabilities, to exploit the potential of the room creating activities with materials freely without any forced interaction flow. Specialists tried to explore activities with available materials for 15 minutes each and took notes when required. We then met them in the focus group, and the moderator asked questions about their experience. The outcomes of this focus group allow us to design phygital activities in the multisensory room properly.

Target. Activities could be played by both neurotypical and children with disabilities, among which not only the ones with physical, visual, or auditory impairments but also with intellectual disabilities (ID). ID is a term used to indicate a set of chronic deficits of cognitive, communicative, and social skills that limit learning, adaptive behavior in everyday life. ID is associated with neurodevelopmental disorders such as autism, Down Syndrome, or learning disorders. It involves $3 \%$ of the population in developed countries [18]. As regards
Fig. 1. The picture captures Magika environment with all its equipment, including material frames, smart objects, and RFID reader (ERA) 
children with visual and auditory impairments, they refer on the one hand to blindness, low vision and color-blindness and on the other hand to deafness and hard-of-hearing deficits. Moreover, we include children with inability to use a mouse or slow response time, and limited fine motor control. Our approach is focusing on offering alternative input devices to let the multisensory room accessible to everyone.

Objective Taxonomy. Thanks to the focus group, we were able to understand and collect some basic educational objectives, from which we design phygital activities. We collected them in the following taxonomy:

1. Primary school cognitive objectives: A. Basic logical categories; B. Space-time concepts; C. Measurement and size concept; D. Hypothesis and causality; E. Socioaffective capacity

2. Disciplinary objectives: A. Chemistry: experiment and understand the properties of materials in a multisensorial context; B. Technology: learn to interact with digital and non-digital tools;

3. Transversal objectives: A. Live multisensorial experiences; B. Participate in communication exchanges, learning the value of confrontation; $C$. Develop reflexive skills, adding personal relevance; D. Knowledge in action: learn to recognize sensory inputs and associate them with physical properties of materials.

As a second step, a collaborative environment is required to let all the children with and without disabilities, both cognitive and physical, play together. For this reason, another important objective is to realize design-for-all activities.

Material Selection. The material samples used in Magika were selected according to technical/ functional requirements and sensorial properties, based on a previous research project [14], where the relation between sensorial properties of materials and associated descriptors was investigated. First, selected materials shall be resistant enough not to be easily damaged by children when they are called to manipulate and explore them actively. Then, materials must fulfill hygienic standards, being washable and non-toxic. Another important aspect is that children cannot be
Table. 1. Selected materials with their ranked properties

\begin{tabular}{|c|c|c|c|c|c|c|c|}
\hline Tag & Colour & Lightness & Texture & Softness & Slipperiness & Deformability & Transparency \\
\hline A1 & Pink & 1 & 2 & 4 & 2 & 2 & 3 \\
\hline A2 & Orange & 1 & 2 & 1 & 3 & 2 & 3 \\
\hline A3 & Light brown & 1 & 2 & 2 & 3 & 3 & 3 \\
\hline A4 & Red & 2 & 2 & 3 & 3 & 3 & 3 \\
\hline A5 & Light green & 2 & 2 & 2 & 2 & 3 & 3 \\
\hline A6 & White & 3 & 2 & 4 & 2 & 5 & 3 \\
\hline B1 & Light pink & 2 & 1 & 5 & 1 & 2 & 2 \\
\hline B2 & Transparency & 2 & 1 & 5 & 1 & 2 & 2 \\
\hline B3 & Blue & 3 & $/$ & 5 & 4 & 4 & 3 \\
\hline B4 & Black & 3 & 3 & 5 & 4 & 3 & 3 \\
\hline B5 & Light grey & 4 & 2 & 5 & 4 & 4 & 3 \\
\hline B6 & Light grey & 4 & 1 & 5 & 1 & 4 & 3 \\
\hline B7 & Black & 4 & 2 & 5 & 4 & 4 & 3 \\
\hline C1 & Green & 2 & $/$ & 3 & 5 & 3 & 3 \\
\hline C2 & Gold & 1 & 1 & 5 & 1 & 1 & 3 \\
\hline D1 & White & 1 & 3 & 3 & 3 & 2 & 2 \\
\hline D2 & White & 1 & 3 & 5 & 2 & 2 & 2 \\
\hline D3 & Grey & 1 & 2 & 4 & 1 & 1 & 3 \\
\hline D4 & Light grey & 4 & 1 & 4 & 4 & 3 & 3 \\
\hline D5 & Blue & 5 & 1 & 5 & 4 & 4 & 3 \\
\hline D6 & Black & 5 & 1 & 3 & 5 & 3 & 3 \\
\hline F1 & White & 1 & 2 & 5 & 3 & 2 & 2 \\
\hline
\end{tabular}


exposed to risk environment where they could get hurt, thus material selection is affected by non-breakable and non-sharp properties. At last, keep in mind our target is fundamental: experience for children with physical or visual impairments could be facilitated choosing material not too heavy or too bulky; as regards users with cognitive disabilities we expect some frustrated behaviours, thus material should be soft enough to avoid any risky situation. Following the above steps, 30 material samples were selected, and then they have been classified by 5 material experts rating them according to 6 material properties (Table 1).

The considered material properties are: lightness (LightHeavy: 1-5 scale); texture (Rough-Smooth: 1-5 scale); softness (Soft-Hard: 1-5 scale); slipperi-ness (SlipperyUnslippery/No fluent: 1-5 scale); transparency (Transparent-Opaque: 1-3 scale); deformability (Stiff - Flexible: 1-5 scale). After ranking materials, they have been tagged to be recognized by the system with RFID tags, according to their material families (A Polyurethane; B - Rubber; C - Composites; D - Fabric; E - Natural Material; F - Smart Material).

Phygital Activity Framework. Since the main goal is to let children play and collaborate through the game and learning about basic knowledge of materials, we designed a framework for phygital activity: on-boarding phase, the first-time children enter the room, they are called to answer simple questions to profile the user; instructions activities, which aims at familiarizing with room and materials; tactile activities, which goal is to explore and learn materials properties. Three interaction are possible: the one with hands, the other with feet and the activities which include both. To provide a modular and flexible activity with materials,

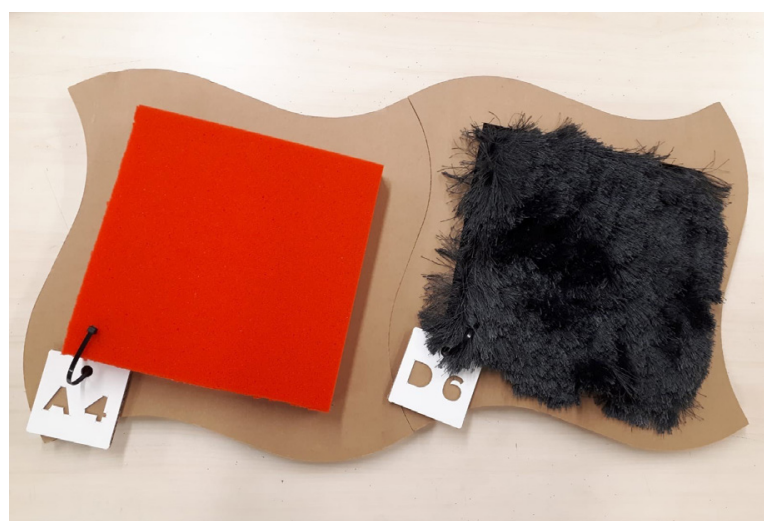

cardboard-frames are produced: bigger frames for feet and smaller ones for hand. For the same reason, two dimensions of material samples, that can be inserted in the frames, are provided (Figure 2).

The flexible approach encourages teachers to build and select their own materials set. To provide an engaging and likable user experience, the activities are explained and presented by an animated cartoon-avatar which looks like the cardboard frame of materials. The onboarding phase is experienced just once followed by the instruction activities, which could be exploited any times teachers require. As concerns the tactile activities, they could be played every time, but they required that both on-boarding and instruction phases have been experienced, otherwise children would be not able to accomplish the task required. The tactile activities are structured in steps:

-Explanation phase: the avatar defines what the activity is focused on (i.e., recognize the correct properties, identify the material association);

-Exploration phase: the avatar shows to the child how to explore the material to recognize and identify correctly the associated property;

-Instruction phase: the avatar gives the instructions to the child explaining which materials take to play with and which task he shall accomplish;

-Action phase: the child fulfills the avatar requirements; -Reward phase: they receive the proper reward if acts correctly.

The materials recognition system is RFID-based: each material is tagged with a label and the system, through a tangible object in the room, could identify if the child took the correct material from the material set [17].

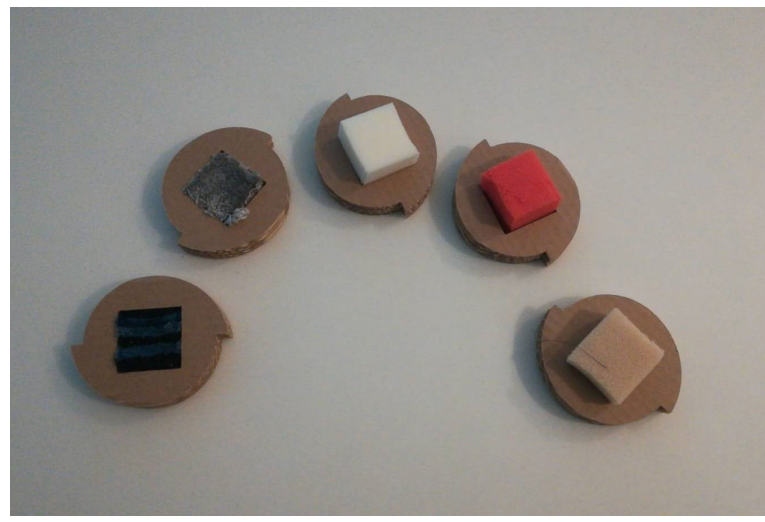

Fig. 2. Material frames: each material is tagged, and it is designed in a modular way. Feetframes (left $-33 \mathrm{~cm}$ $\times 33 \mathrm{~cm}$ ), hand-frame (right $-10 \mathrm{~cm} \times 10$ $\mathrm{cm})$. 


\section{Results}

Design Phygital Activities. The on-boarding phase has been defined accurately for profiling users.

Magika gathers data regarding their preferences about materials, not only referring to their likability but also question them about sound-material or imagematerial associations to adapt each activity to the user preferences, and to avoid any unexpected behaviour from children with disabilities (i.e., aggressive reactions). This information could also be used during tactile activities. Instruction activities are designed independently from that just to let children get familiar with the room. As a result of the focus group session, the tactile activities are:

-Memory-tactile game: children shall identify and couple two items of the same material exploring them with their hands, and as classical memory game required, they shall remind their correct positions.

-Twin-tactile game: children are required to match the material they explore by feet and the one they experience through hands.

-Scaling game: children explore materials, and they are called to rank them according to the proposed property in crescent or descent order. This game provides a different difficulty level, which is adapted to the user knowledge and expertise.

-Storytelling game: children are immersed in a story, where they are required to accomplish a specific task to go through the narration, mainly based on sensorial associations.

Phygital activities have been designed following the objectives guidelines elicited by specialists discussed in the previous section. In Table 2, the activities and their main features are collected.

Design Principles. To define design principles, we specifically asked specialists to express opinions on the usability of phygital activities and personal will to use it in everyday school or center-routine. We asked them to focus on the design and the mandatory features that might be added to activities in the room according to their expertise. All specialists were willing to contribute and pointed out some design guidelines when developing phygital activities in the form of potential requirements. The design principles elicited for the creation of phygital activities are:
Table. 2. Designed activities and their main features

\begin{tabular}{|c|c|c|c|c|c|c|}
\hline \multicolumn{2}{|c|}{ Designed activities } & Objectives & Target & Tools & Players & Design Principles \\
\hline \multicolumn{2}{|c|}{ On-boarding } & $\begin{array}{c}1 \mathrm{~A}, 1 \mathrm{C}, 1 \mathrm{D} \\
2 \mathrm{~B}, 3 \mathrm{~A}\end{array}$ & $\begin{array}{l}\text { Children with and } \\
\text { without disabilities }\end{array}$ & $\begin{array}{c}\text { Digital projections, } \\
\text { Sounds }\end{array}$ & Individual & $\begin{array}{c}\text { Adaptivity, Aesthetics, } \\
\text { Design-for-all }\end{array}$ \\
\hline \multicolumn{2}{|c|}{ Instruction Activities } & $\begin{array}{c}1 \mathrm{~A}, 1 \mathrm{~B}, 1 \mathrm{C}, 1 \mathrm{D} \\
2 \mathrm{~B}, 3 \mathrm{~A}, 3 \mathrm{~B}\end{array}$ & $\begin{array}{l}\text { Children with and } \\
\text { without disabilities }\end{array}$ & $\begin{array}{l}\text { Digital projections, } \\
\text { Sounds, Hand/Foot- } \\
\text { frames }\end{array}$ & $\begin{array}{l}\text { Individual/ } \\
\text { Group }\end{array}$ & Aesthetics, Design-for-all \\
\hline \multirow[t]{4}{*}{\begin{tabular}{c|} 
Tactile \\
Activities
\end{tabular}} & $\begin{array}{l}\text { Memory- } \\
\text { tactile }\end{array}$ & $\begin{array}{c}1 \mathrm{~A}, 1 \mathrm{~B}, 1 \mathrm{C} \\
1 \mathrm{D}, 2 \mathrm{~A}, 2 \mathrm{~B} \\
3 \mathrm{~A}, 3 \mathrm{~B}\end{array}$ & $\begin{array}{l}\text { Children with and } \\
\text { without disabilities }\end{array}$ & $\begin{array}{l}\text { Digital projections, } \\
\text { Sounds, Hand/Foot- } \\
\text { frames }\end{array}$ & $\begin{array}{l}\text { Individual/ } \\
\text { Group }\end{array}$ & $\begin{array}{c}\text { Adaptivity, Aesthetics, } \\
\text { Design-for-all, } \\
\text { Controllability, Flexibility }\end{array}$ \\
\hline & Twin-tactile & $\begin{array}{c}1 \mathrm{~A}, 1 \mathrm{~B}, 1 \mathrm{C} \\
1 \mathrm{D}, 2 \mathrm{~A}, 2 \mathrm{~B} \\
3 \mathrm{~A}, 3 \mathrm{~B}\end{array}$ & $\begin{array}{l}\text { Children with and } \\
\text { without disabilities }\end{array}$ & $\begin{array}{c}\text { Digital projections, } \\
\text { Sounds, Hand/Foot- } \\
\text { frames }\end{array}$ & $\begin{array}{l}\text { Individual/ } \\
\text { Group }\end{array}$ & $\begin{array}{l}\text { Adaptivity, Aesthetics, } \\
\text { Design-for-all, } \\
\text { Controllability, Flexibility }\end{array}$ \\
\hline & Scaling game & $\begin{array}{c}1 \mathrm{~A}, 1 \mathrm{~B}, 1 \mathrm{C} \\
1 \mathrm{D}, 2 \mathrm{~A}, 2 \mathrm{~B} \\
3 \mathrm{~A}, 3 \mathrm{~B}, 3 \mathrm{C} \\
3 \mathrm{D}\end{array}$ & $\begin{array}{l}\text { Children with and } \\
\text { without disabilities }\end{array}$ & $\begin{array}{l}\text { Digital projections, } \\
\text { Sounds, Hand/Foot- } \\
\text { frames }\end{array}$ & $\begin{array}{l}\text { Individual/ } \\
\text { Group }\end{array}$ & $\begin{array}{c}\text { Adaptivity, Aesthetics, } \\
\text { Design-for-all, } \\
\text { Controllability, Flexibility }\end{array}$ \\
\hline & Storytelling & $\begin{array}{c}1 \mathrm{~A}, 1 \mathrm{~B}, 1 \mathrm{C} \\
1 \mathrm{D}, 2 \mathrm{~A}, 2 \mathrm{~B} \\
3 \mathrm{~A}, 3 \mathrm{~B}, 3 \mathrm{C} \\
3 \mathrm{D}\end{array}$ & $\begin{array}{l}\text { Children with and } \\
\text { without disabilities }\end{array}$ & $\begin{array}{l}\text { Digital projections, } \\
\text { Sounds, Hand/Foot- } \\
\text { frames, Smell }\end{array}$ & $\begin{array}{l}\text { Individual/ } \\
\text { Group }\end{array}$ & $\begin{array}{c}\text { Adaptivity, Aesthetics, } \\
\text { Design-for-all, } \\
\text { Controllability, Flexibility }\end{array}$ \\
\hline
\end{tabular}


-Adaptivity. Before starting to play in the room, the system needs to know which stimuli users like most and the ones which could create frustration to them: Magika collect this information for adapt the phygital activities according to the user during the on-boarding phase.

-Aesthetics. In our project, this aspect is linked to the exploration of the expressive-sensorial properties of materials, generally used by designers to emotionally engage the user. Through the activities of stories, we try to create an immersive environment in which to educate to the multisensory experience through stimuli and visual-tactile and olfactory associations. The intelligent environment favors the repetition of associations preferred by the user and tries not to propose those critical to the subject.

-Controllability. We have also designed a tool to tackle complexity in this technology-enriched system to let teachers control the multisensory room. The tabletbased app allows teachers to manage the whole experience and it contains three different sections: Create, where teacher can build their custom activities; Play, where teacher can choose which activities to perform during a session in the multisensory room; Live, which is a control panel thank to which teacher can go ahead during an activity even if the system is not working properly (i.e., Kinect is not detecting precisely the child position).

-Design-for-all. Activities are designed to provide information to children through different channels, both visual and auditive. Following the principle of design-forall, Magika becomes an inclusive environment where other children adjust their interaction modes according to the ones with impairments (reverse-inclusion).

Multisensory environments also allow a wide range of people with different perceptive and cognitive abilities to play actively in the room.

\section{-Flexibility. The teacher can introduce new custom} materials which could be used during the activities in the room. They are free to enlarge the material kit and create new activity according to their needs using the Create section of Magika tablet-based app.
Designers are required to multidisciplinary and openness towards an evolving system design (in our case activities). In fact, we did not think about activities related only to the materials provided but based on the preferences of the children or those of the teacher, trying to encourage the implementation of new materials. The critical aspect is their use in property classification activities; however, they could be used in stories and/or other games (or relaxation, etc.). Since the two rooms have been installed in two primary schools, we tested our phygital activities in an educational environment. Children performed an explorative session where they played with the designed activities in the room. All design principles played a key role in supporting children activities in the room. A methodical experimental study will be performed for providing evidence on the effectiveness of the design process.

\section{Conclusion and Future Work}

To achieve its goals, the project must necessarily embrace a multidisciplinary approach. In technological terms, the project requires advanced system integration, Internet of Things, physical systems, interactive olfactory systems, and physical exploration of materials. To design the Magika physical space, the "smart" objects, and their interactive properties, different skills from the design field are needed (UX, UI, interior and product design) [16]. The definition of stimuli and activities for children involves the educational and therapeutic skills of professionals in disability. These multidisciplinary requirements guided the definition of the working group and the partners. The innovation of the project is also in experimentation, unique in its kind for complexity and size. The empirical validations of interactive technology for individuals with disabilities are intrinsically very difficult, and the total of participants in existing empirical studies varies between 3 and 20. The project team has installed two Magika Room solutions in real contexts (two primary schools in suburbs-city) and will conduct an experiment on the field involving over 800 children with disabilities of 10 municipalities in the Milan suburbs, 58 teachers, and 51 classes. In this complex digital-physical ecosystem, a schematic experimental approach will be adopted to collect valuable information regarding user experience. 


\section{Acknowledgments. The project has been funded by Politecnico Social Award 2017. We gratefully thank all the sponsors and partners for their help and the material suppliers for donating material samples.}

\section{References}

1. F. Celaschi, R. Montanari, U. Suor, O. Benincasa, G. Padula, S Marino, Approcci all'innovazione trainata dal design, MD J. 4 (2017) 74-85

2. A. Branzi, Modernità debole e diffusa. II mondo del progetto all'inizio del XXI secolo, Skira, Milano, 2006.

3. http://ilgiornaledellarchitettura.com/web/2017/10/25/luisabocchietto-il-design-e-diventato-adulto/.

4. S. Bowen, A. Durrant, B. Nissen, J. Bowers, P. Wright, The value of designers' creative practice within complex collaborations, Des. Stud. 46 (2016). doi:10.1016/j. destud.2016.06.001

5. J.W. Arnold, et al., Designer Evolution : a Story of Reconciliation Between Creativity and Research in Industrial Design, Design. (2006)

6. M. Hölter, A. Piselli, S. Colombo, B. Del Curto, A material database framework to support the design of shapechanging product, in: IHSI 2019, San Diego, n.d.

7. L. Yao, Shape Changing Composite Material Design for Interactions, Massachusetts Institute of Technology, 2017.

8. B. Barati, E. Giaccardi, E. Karana, The Making of Performativity in Designing [ with ] Smart Material Composites, Proc. CHI'18. (2018) 1-11. doi:10.1145/3173574.3173579.

9. M. Ashby, K. Johnson, Materials and design: the art and science of material selection in product design, Oxford, 2002.

10. M. Ashby, H. Shercliff, D. Cebon, Materials: Engineering, Science, Processing and Design, London, 2007.

11. O. Pedgley, V. Rognoli, E. Karana, Materials experience as a foundation for materials and design education, Int. J. Technol. Des. Educ. 26 (2016). doi:10.1007/s10798-015-9327-y.

12. Organisation for Economic Cooperation and Development. 2012. Special Educational Needs. (May 2012). http://www. oecd.org/els/family/50325299.pdf

13. Gelsomini, Mirko, et al. "Magika, a Multisensory Environment for Play, Education and Inclusion." Extended Abstracts of the 2019 CHI. ACM, 2019.

14. Piselli A. et al., "Sensory Analysis techniques for materials selection in the education and in the industry context." 9th International Materials Education Symposium. 2017.
15. http://www.dipartimentodesign.polimi.it/en/conosci-mariobisson-eng

16. Arquilla $\vee$. et al., A cooperative model between university and social alliances for enabling young students to face practical and ethical issues in the design process leading to social innovation: the Cometa experience, ICERI 2014 Proceedings, IATED

17. Karime, Ali, et al. "RFID-based interactive multimedia system for the children." Multimedia Tools and Applications 59.3 (2012): 749-774

18. American Psychiatric Association, 2013. Diagnostic and statistical manual of mental disorders (DSM-5®). American Psychiatric Pub.

19. Guralnick, M.J. and Bennett, F.C., 1987. The effectiveness of early intervention for at-risk and handicapped children. Academic Press.

20. Smith, T, et al. 2000. Randomized trial of intensive early intervention for children with pervasive developmental disorder. American Journal on Mental Retardation.

21. Bronfenbrenner, U. Is early intervention effective? Early Childhood Education Journal 1974.

22. Caballé, Santi, et al. "CC-LR: providing interactive, challenging and attractive Collaborative Complex Learning Resources." Journal of Computer Assisted Learning 30.1 (2014).

23. Wilson, Margaret. Six views of embodied cognition. Psychonomic bulletin \& review (2002).

24. Antle et al. "The CTI framework: informing the design of tangible systems for children." TEI. ACM, 2007.

25. Falcão, Taciana Pontual. "Action-effect mappings in tangible interaction for children with intellectual disabilities." International Journal of Learning Technology 12.4 (2017).

26. Eisenberg, Michael, et al. "As we may print new directions in output devices and computational crafts for children." Proceedings of the 2003 conference on Interaction design and children. ACM, 2003.

27. Johnson, K. W., Langdon, P. M., \& Ashby, M. F. (2002). Grouping materials and processes for the designer: an application of cluster analysis. Materials \& design.

28. Del Curto, B., et al. (2010). LA PELLE DEL DESIGN Progettare la sensorialità. Lupetti.

29. Karana, E., Barati, B., Rognoli, V., Der Laan, V., \& Zeeuw, A. (2015). Material driven design (MDD): A method to design for material experiences.

30. Wilkes, K. V. (2014). Physicalism. Routledge.

31. Karana, E., Hekkert, P., \& Kandachar, P. (2009). Meanings of materials through sensorial properties and manufacturing 
processes. Materials \& Design, 30(7), 2778-2784.

32. Orlandi et al. "Experimental experience in design education as a resource for innovative thinking: The case of Bruno Munari." Procedia-Social and Behavioral Sciences 2.2 (2010). 33. Wilson, M. (2002). Six views of embodied cognition. Psychonomic bulletin \& review.

34. Lancioni, G. E., Cuvo, A. J., \& O'reilly, M. F. (2002). Snoezelen: an overview of research with people with developmental disabilities and dementia. Disability and rehabilitation.

35. Pares, $\mathrm{N}$ et al. (2005). Achieving dialogue with children with severe autism in an adaptive multisensory interaction: the" MEDIATE" project. IEEE.

36. http://www.polisocial.polimi.it/it/home/ 